\title{
Unilateral chronic insufficiency of anterior cruciate liga- ment decreases bone mineral content and lean mass of the injured lower extremity
}

\author{
Shinjiro Takata, Aziz Abbaspour, Michiharu Kashihara, Shigetaka Nakao, and \\ Natsuo Yasui \\ Department of Orthopedics, Institute of Health Bioscieces, The University of Tokushima Graduate \\ School, Tokushima, Japan
}

\begin{abstract}
We studied the effects of unilateral chronic anterior cruciate ligament (ACL) injury on bone size, bone mineral content (BMC), bone mineral density (BMD), soft tissue composition and muscle strength of the injured lower extremity in Japanese 21 men and 12 women aged 15 to 39 years. Bone area, BMD, BMC, lean mass and fat mass of lower extremity were measured using dual energy $X$-ray absorptiometry. The isometric and isokinetic muscle strength was assessed by an isokinetic machine.

BMC, lean mass, circumference of the thigh and circumference of the lower leg of the injured lower extremity were significantly smaller than those of the intact lower extremity $(p=0.0002, p<0.0001, p<0.0001, p=0.0131)$. In cotrast, fat mass and \%Fat of the injured lower extremity was significantly greater than that of the intact lower extremity $(p=$ $0.0301, p<0.0001)$. Bone area and BMD did not produce significant difference. These findings suggest that chronic insufficiency of ACL decreases BMC and lean mass of the injured lower extremity. J. Med. Invest. 54 : 316-321, August, 2007
\end{abstract}

Keywords : anterior cruciate ligament injury, bone area, bone mineral content, bone mineral density, dual energy X-ray absorptiometry

\section{INTRODUCTION}

ACL injury is a common knee trauma in sports, and it often causes chronic symptomatic instability (1) and proprioceptive deficit of the knee on the injured side (2). Chronic instability of the knee joint resulting from ACL injury induces muscle atrophy $(3,4)$, muscle weakness $(2,5)$, and degenerative changes of the knee joint (1), and bone atrophy of the leg on the injured side $(6,7)$.

Received for publication June 15, 2007 ; accepted July 4, 2007.

Address correspondence and reprint requests to Shinjiro Takata, M.D., Ph.D., Department of Orthopedics, Institute of Health Biosciences, The University of Tokushima Graduate School, Kuramoto-cho, Tokushima 770-8503, Japan and Fax : +81-88-6330178 .
Mechanical stress is an important determinant to prevent musculoskeletal atrophy of the lower extremity. Therefore, reduction of mechanical stress on the legs in patients with unilateral ACL injury may lead to diminution of the synthesis of contractile protein and bone formation, which may result in disuse musculoskeletal atrophy of the lower extremity on the injured side. Hence, early and vigorous rehabilitation is required to prevent disuse musculoskeletal atrophy of the lower extremity, so that patients with ACL injury can return to sports as early as possible $(8,9)$.

The purpose of this study was to clarify the effects of unilateral ACL injury on bone area, BMC, BMD and soft tissue composition of lower extremity. The question of whether chronic ACL injury de- 
creases bone size of the injured lower extremity or not has not been adequately solved.

\section{MATERIALS AND METHODS}

Twenty-one men and twelve women with unilateral untreated ACL injury, whose age ranged from 15 to 39 years were studied. Table 1 showed characteristics of men and women with unilateral untreated ACL injury. In all patients, pivot-shift and Lachman's test were positive. Thirty-two of 33 patients underwent ACL reconstruction surgery with a central third patellar tendon graft (bone-patellar tendon-bone graft) (10).

All subjects agreed to participate in this study and gave their informed consent.

Measurement of bone area, BMD, BMC, lean mass and fat mass of lower extremity by dual energey $X$ ray absorptiometry

Bone area, BMD, BMC, fat mass, and lean mass of lower extremity were measured by dual energy X-ray absorptiometry (DXA) using a QDR-2000 densitometer (Hologic Inc., Waltham, MA. USA) in the array beam scanning mode (Enhanced Array Whole Body, version 5.60A). Regional bone area $\left(\mathrm{cm}^{2}\right)$ and BMD $\left(\mathrm{g} / \mathrm{cm}^{2}\right)$ was measured in the head, upper extremities, lower extremities, ribs, thoracic spine, lumbar spine and pelvis. The lean mass (g), fat mass (g) and \%Fat (\%) of the head, upper extremities, lower extremities and trunk was measured with a tissue bar $(11,12)$. In our preliminary study, there was no significant difference of bone area, BMD, $\mathrm{BMC}$, lean mass, fat mass and \%Fat between dominant and non-dominant legs.

Figure shows the screen display of total bone mineral in vivo. Lines superimposed upon the skeleton demarcate major anatomical areas, head, upper extremities, ribs, thoracic spine, lumbar spine, pelvis and lower extremities. The horizontal line above the shoulders should be just below the chin. The vertical lines at the shoulders should be between the head of the humerus and scapula at the glenoid fossa. The vertical lines on either side of the spine should be moved close to the spine. The small horizontal line should be approximately at the level of L1-T12. The horizontal line above the pelvis should be just above the crest of the ilium. This line can be extended out at the sides to include soft tissue in the chest and waist. The angled lines below the pelvis should bisect both femoral necks. The vertical line between the lower extremities should be adjusted to be between the feet. The vertical lines lateral to the lower extremities should be adjusted to include as much of the soft tissue as possible in the thighs.

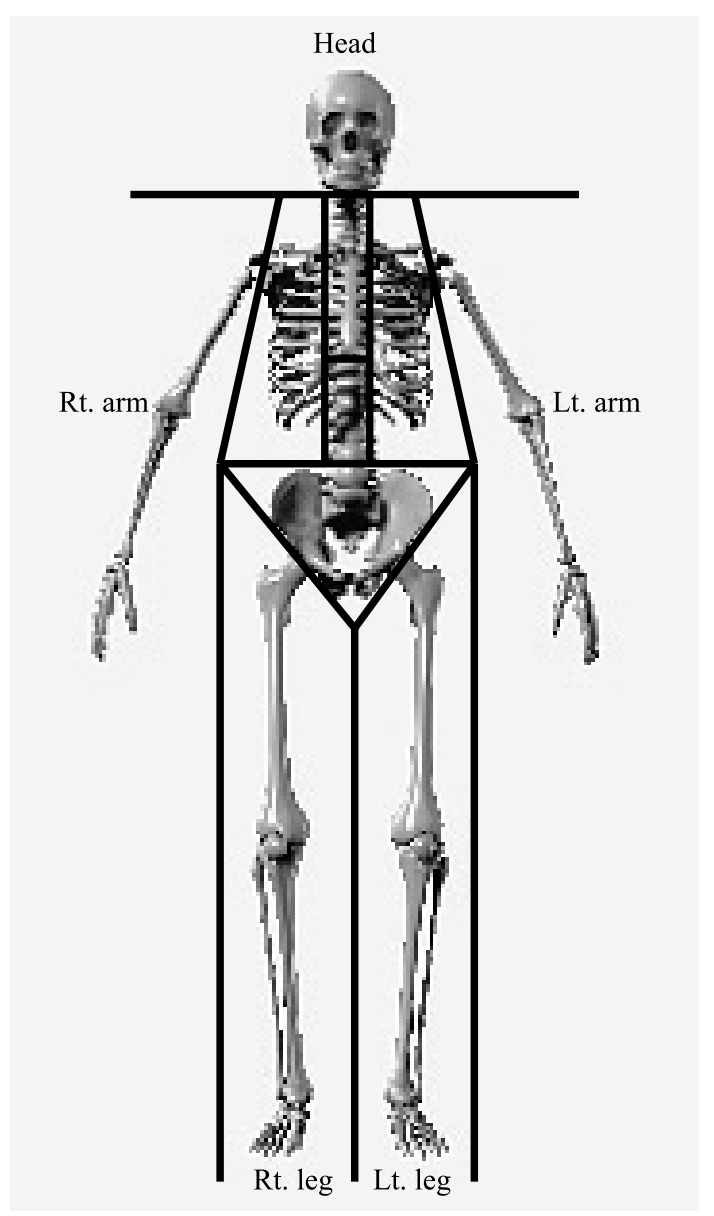

Figure Screen display of total bone mineral in vivo. Lines superimposed upon the skeleton demarcate major anatomical areas, head, upper extremities, ribs, thoracic spine, lumbar spine, pelvis and lower extremities.

\section{Muscle strength}

The isometric muscle strength of quadriceps and hamstrings muscles was measured with the knee

Table 1. Characteristics of men and women with unilateral ACL injury

\begin{tabular}{lccccc}
\hline & $\begin{array}{c}\text { Age } \\
(\mathrm{y})\end{array}$ & $\begin{array}{c}\text { Body height } \\
(\mathrm{cm})\end{array}$ & $\begin{array}{c}\text { Body weight } \\
(\mathrm{kg})\end{array}$ & $\begin{array}{c}\text { BMI } \\
\left(\mathrm{kg} / \mathrm{m}^{2}\right)\end{array}$ & $\begin{array}{c}\text { Time from injury to admission } \\
(\text { month })\end{array}$ \\
\hline Men $(\mathrm{n}=21)$ & $21.3 \pm 6.2$ & $172.6 \pm 4.1$ & $66.5 \pm 5.9$ & $22.4 \pm 2.3$ & $11.6 \pm 14.3$ \\
Women $(\mathrm{n}=12)$ & $26.3 \pm 8.2$ & $161.3 \pm 4.7$ & $59.1 \pm 8.0$ & $22.7 \pm 3.0$ & $16.7 \pm 15.0$ \\
\hline
\end{tabular}

BMI, body mass index 
joint flexed in 45 degrees. The isokinetic muscle strength was assessed as a peak torque $(\mathrm{Nm})$. The peak torque of the quadriceps and hamstrings was determined at a low-speed of 60 (degrees per second) and a high-speed of 180 (degrees per second) by means of an isokinetic machine using Cybex II. The injured/intact ratio of peak torque was compared between hamstring and quadriceps muscles at low-speed and high-speed to evaluate muscular contractility of the injured lower extremity.

Circumference of the thigh and circumference of the lower leg

The circumference of the thigh (COT) was measured at a point $10 \mathrm{~cm}$ proximal to the patellar superior pole, and the circumference of the lower leg (COLL) at the point of maximal diameter of the lower leg.

\section{Statistics}

Results were expressed as the mean \pm standard deviation. Student's paired t-test was used for differences between injured and intact legs of all patients. Spearman's rank correlation coefficients were calculated to correlate the time from injury to admission and injured lower extremity / intact lower extremity ratio of $\mathrm{BMD}, \mathrm{BMC}$, lean mass, fat mass, \%fat, COT, COLL, muscle. A p value of less than 0.05 was considered to be statistically significant.

\section{RESULTS}

Bone area, BMD, BMC, lean mass, fat mass, \%fat, COT and COLL (Table 2).

Significant effect of unilateral ACL injury on BMC, lean mass, fat mass, \%fat, COT and COLL of the injured lower extremity was detected in this study.

$\mathrm{BMC}$, lean mass, COT and COLL of the injured lower extremity were significantly smaller than those of the intact lower extremity $(\mathrm{p}=0.0002, \mathrm{p}<0.0001$, $\mathrm{p}<0.0001, \mathrm{p}=0.0131)$. In contrast, fat mass and $\% \mathrm{Fat}$ of the injured lower extremity were significantly greater than those of the intact lower extremity $(p=0.0301, p<0.0001)$.

\section{Muscle strength of hamstring and quadriceps mus-} cles (Table 3).

The isometric muscle strength of hamstrings and quadriceps muscles of the injured lower extremity were significantly smaller than those of the intact lower extremity $(\mathrm{p}<0.0001, \mathrm{p}=0.0003)$.

The isokinetic muscle strength, as expressed by peak torque $(\mathrm{Nm})$, of the hamstring muscle of the injured lower extremity were significantly smaller than those of the intact lower extremity at low-speed and high speed $(\mathrm{p}=0.0005, \mathrm{p}=0.0006)$. The isokinetic muscle strength of the quadriceps muscle of the injured lower extremity were significantly smaller than those of the intact lower extremity at low-speed and high speed $(p=0.0003, p=0.0037)$.

Table 2. Bone area, BMD, BMC, lean mass, fat mass, COT and COLL of injured and intact lower extremities of all patients.

\begin{tabular}{|c|c|c|c|c|c|}
\hline & $\begin{array}{l}\text { Bone area } \\
\left(\mathrm{cm}^{2}\right)\end{array}$ & $\begin{array}{c}\mathrm{BMD} \\
\left(\mathrm{g} / \mathrm{cm}^{2}\right)\end{array}$ & $\begin{array}{c}\mathrm{BMC} \\
(\mathrm{g})\end{array}$ & $\begin{array}{l}\text { Lean mass } \\
\quad(g)\end{array}$ & $\begin{array}{l}\text { Fat mass } \\
(\mathrm{g})\end{array}$ \\
\hline Injured lower extremity & $388.3 \pm 87.3$ & $1.22 \pm 0.22$ & $475.2 \pm 103.1$ & $7,421.4 \pm 1,444.6$ & $2,931.6 \pm 1,186.8$ \\
\hline Intact lower extremity & $405.1 \pm 94.9$ & $1.23 \pm 0.18$ & $493.0 \pm 105.2$ & $7,821.3 \pm 1,507.1$ & $2,861.0 \pm 1,148.3$ \\
\hline \multirow[t]{2}{*}{$\mathrm{p}$ value } & 0.1995 & 0.6806 & 0.0002 & $<0.0001$ & 0.0301 \\
\hline & $\begin{array}{l}\% \text { Fat } \\
(\%)\end{array}$ & $\begin{array}{l}\text { COT } \\
(\mathrm{cm})\end{array}$ & $\begin{array}{l}\text { COLL } \\
(\mathrm{cm})\end{array}$ & & \\
\hline Injured lower extremity & $27.0 \pm 10.5$ & $43.4 \pm 3.1$ & $35.5 \pm 2.7$ & & \\
\hline Intact lower extremity & $25.3 \pm 9.9$ & $44.7 \pm 3.5$ & $36.0 \pm 2.9$ & & \\
\hline $\mathrm{p}$ value & $<0.0001$ & $<0.0001$ & 0.0131 & & \\
\hline
\end{tabular}

Values given as the mean \pm standard deviation.

$\mathrm{BMD}$, bone mineral density ; BMC, bone mineral content ; COT, circumference of the thigh ; COLL, circumference of the lower leg 
Table 3. Muscle strength of quadriceps and hamstring muscles of injured and intact lower extremities of all patients. (A) Hamstring muscle strength

\begin{tabular}{lccc}
\hline & Isometric & $\begin{array}{c}\text { Low-speed } \\
\text { (60 degrees/second) }\end{array}$ & $\begin{array}{c}\text { High-speed } \\
\text { (180 degrees/second) }\end{array}$ \\
\hline Injured lower extremity $(\mathrm{Nm})$ & $81.6 \pm 34.4$ & $64.9 \pm 25.6$ & $62.5 \pm 22.9$ \\
Intact lower extremity $(\mathrm{Nm})$ & $98.9 \pm 35.9$ & $83.0 \pm 28.1$ & $76.0 \pm 24.9$ \\
p value & $<0.0001$ & 0.0005 & 0.0006 \\
\hline
\end{tabular}

Values given as the mean \pm standard deviation.

(B) Quadriceps muscle strength

\begin{tabular}{lccc}
\hline & Isometric & $\begin{array}{c}\text { Low-speed } \\
\text { (60 degrees / second) }\end{array}$ & $\begin{array}{c}\text { High-speed } \\
(180 \text { degrees / second) }\end{array}$ \\
\hline Injured lower extremity (Nm) & $155.7 \pm 74.8$ & $107.4 \pm 52.1$ & $99.8 \pm 47.2$ \\
Intact lower extremity (Nm) & $197.4 \pm 73.2$ & $156.4 \pm 57.5$ & $127.1 \pm 42.0$ \\
p value & 0.0003 & 0.0003 & 0.0037 \\
\hline
\end{tabular}

Values given as the mean \pm standard deviation.

Table 4. Relationship between the time from injury to admission and injured lower extremity / intact lower extremity ratio of Bone area, BMD, BMC, fat mass, lean mass, muscle strength and COT, COLL of all patients.

\begin{tabular}{lcc}
\hline & $\rho$ & p value \\
\hline Inj/int Bone area of the lower extremity & 0.208 & 0.247 \\
Inj/int BMD of the lower extremity & -0.232 & 0.197 \\
Inj/int BMC of the lower extremity & -0.249 & 0.166 \\
Inj/int Fat of the lower extremity & -0.388 & 0.031 \\
Inj/int Lean of the lower extremity & 0.111 & 0.538 \\
Inj/int Hamstring muscle strength & & 0.056 \\
$\quad$ isometric & -0.530 & 0.775 \\
$\quad$ low-speed (60 degrees/second) & -0.079 & 0.344 \\
high-speed (180 degrees/second) & -0.263 & 0.918 \\
Inj/int Quadriceps muscle strength & & 0.468 \\
$\quad$ isometric & & 0.029 \\
low-speed (60 degrees/second) & -0.206 & 0.788 \\
Inj/int COT & -0.075 & 0.812
\end{tabular}

BMD, bone mineral density ; BMC, bone mineral content ; COT, circumference of the thigh ; COLL, circumference of the lower leg

Relationship between the time from injury to admission and injured lower extremity / intact lower extremity ratio of $B M D, B M C$, lean mass, fat mass, \%fat, COT, COLL, muscle strength (Table 4).

The time from injury to admission to our hospital was 3 to 60 months, with an average of $14.5 \pm 15.0$ months. There was a significant negative correlation between the time from injury to admission and injured / intact ratio of fat mass of lower extremities $(\mathrm{p}=0.031)$.

\section{DISCUSSION}

Chronic unilateral ACL insufficiency reduced BMC of the injured lower extremity, whereas BMD did not change between the injured lower extremity and intact lower extremity. Kannus, et al. (7) showed that a cruciate ligament injury resulted in decreased BMD of the distal femur, patella and proximal tibia in the injured knee. In this study, we measured BMC, BMD and the soft tissue composition of the lower extremity as shown in Figure. In the future study, 
we should measure the BMDs of the proximal femur, distal femur, patella, proximal tibia and calcaneus of both lower extremities to study the effects of an unilateral ACL injury on BMD.

The most important determinant to maintain the BMD of weight bearing bones is the mechanical load applied to the bones. Osteocytes embedded in the bone matrix play an important role in responding to mechanical stress on bone and metabolism changes in bone (13-15). Osteocytes have long processes to conduct mechanical load to other osteocytes, osteoblasts or osteoclasts (16). The gap junction of the long processes enables osteocytes to transmit mechanical stress to facilitate bone formation by osteoblasts while inhibiting bone resorption by osteoclasts in axial bones and appendicular bones. Except for the acute period after ACL injury, these patients could walk with full weight bearing, which may prevent reduction of the BMD of the injured leg in spite of the decrease in BMC.

ACL injury was associated with a reduction of the muscle strength of the injured lower extremity in this study, which is ascribable to disuse muscle atrophy resulting from a decrease in the synthesis of contractile proteins and acceleration of degradation of muscle proteins. In addition, the degree of loss of quadriceps muscle peak torque at low-speed was greater than that of the hamstring muscle, indicating that the quadriceps muscle on the ACL-injured side is more susceptible to lose muscle strength and muscle mass than the hamstrings muscles. The quadriceps muscle is one of the antigravity muscles. Therefore, quadriceps muscles may be predominantly affected by disuse and immobilization than hamstrings muscles. Previous studies have shown that chronic ACL injury affects predominantly quadriceps muscles compared with hamstrings muscles $(2,5,17,18)$, and that it particularly affects the vastus medialis muscles within quadriceps muscles (18). Weakness and atrophy of the quadriceps muscles on the injured side, as shown in the present study, may have been due to selective muscle atrophy of the vastus medialis muscle.

There was a significant negative correlation between injured / intact ratio of fat mass of lower extremities and the time from injury to admission, as shown in Table $3(\mathrm{p}=0.031)$. Based on this fact, fat mass of the injured lower extremity changed with time more markedly than the lean mass of the injured lower extremity.

The present study was just a cross sectional study of patients with unilateral ACL injury before
ACL reconstruction. Therefore, a longitudinal study should be carried out to clarify the effects of surgery on the musculoskeletal system of the lower extremity.

\section{REFERENCES}

1. McDaniel WJ, Dameron TB : The untreated anterior cruciate ligament injury. Clin Orthop 173 : 158-163, 1983

2. Corrigan JP, Cashman WF, Brady MP : Proprioception in the cruciate deficient knee. J Bone Joint Surg 74B(2) : 247-250, 1992

3. Murray SM, Warren RF, Otis JC, Kroll M, Wickiewicz TL: Torque-velocity relationships of the knee extensor and flexor muscles in individuals sustaining injuries of the anterior cruciate ligament. Am J Sports Med 12 : 436-440, 1984

4. Tegner Y, Lysholm J, Gillquist J, Oberg B : Two-year follow-up of conservative treatment of knee ligament injuries. Acta Orthop Scand 55 : 176-180, 1984

5. Baugher WH, Warren RF, Marshall JL, Joseph A : Quadriceps atrophy in the anterior cruciate insufficient knee. Am J Sports Med 12 : 192-195, 1984

6. Sievanen H, Kannus P, Heinonen A, Oja P, Vuori I: Bone mineral density and muscle strength of lower extremities after long-term strength training, subsequent knee ligament injury and rehabilitation : A unique 2-year followup of a 26-year-old female student. Bone 15 (1) : 85-90, 1984

7. Kannus P, Sievanen H, Jarvinen M, Heinonen A, Oja P, Vuori I : A cruciate ligament injury produces considerable, permanent osteoporosis in the affected knee. J Bone Miner Res 7 (12) : 1429-1434, 1992

8. Curl WW, Markey KL, Mitchell WA : Agility training following anterior cruciate ligament reconstruction. Clin Orthop $172: 133-136,1983$

9. Steadman JR: Rehabilitation of acute injuries of the anterior cruciate ligament. Clin Orthop $172: 129-132,1983$

10. Clancy WG, Nelson DA, Reider B : Anterior cruciate ligament reconstruction using one third of the patellar ligament, augmented by extra-articular tendon transfer. J Bone Joint Surg 62A : 352-359, 1982

11. Takata S, Ikata $\mathrm{T}$, Yonezu $\mathrm{H}$ : Characteristics 
of regional bone mineral density and soft tissue mass in patients with atraumatic vertebral fractures. J Bone Miner Metab 18(5) : 287-290, 2000

12. Takata S, Ikata T, Yonezu H, Inoue A : Effects of lower leg lengthening on bone mineral density and soft tissue composition of legs in a patient with achondroplasia. J Bone Miner Metab 18(6) : 339-341, 2000

13. Cowin SC, Moss SL, Moss ML: Candidate for the mechanosensor system in bone. J Biomech Eng 113(2) : 191-197, 1982

14. Doty SB : Morphological evidence of gap junctions between bone cells. Calcif Tissue Int 33 (5) : 509-512, 1981

15. Lanyon LE : Osteocyte, strain detection, bone modeling and bone remodeling. Calcif Tissue
Int 53 : S102-S107, 1993

16. Palumbo C, Palazzini S, Marotti G : Morphological study of intercellular junctions during osteocytes differentiation. Bone 11(6) : 401-406, 1990

17. Nakamura T, Kurosawa H, Kawahara H, Watarai $\mathrm{K}$, Miyashita $\mathrm{H}$ : Muscle fiber atrophy in the quadriceps in knee-joint disorders. Histochemical studies on 112 cases. Arch Orthop Trauma Surg 105(3) : 163-169, 1986

18. Gerber C, Hoppeler H, Claassen H, Robotti G, Zehnder R, Jakob RP: The lower-extremity musculature in chronic symptomatic instability of the anterior cruciate ligament. J Bone Joint Surg 67-A : 1034-1043, 1985 